\title{
Transmission of the Global Financial Crisis to the East Asian Equity Markets
}

\author{
Tran Phuong Thao ${ }^{1,2}$, Kevin Daly ${ }^{1} \&$ Craig Ellis ${ }^{1}$ \\ ${ }^{1}$ School of Business, University of Western Sydney, Sydney, Australia \\ ${ }^{2}$ Department of Banking, University of Economics Ho Chi Minh City, Vietnam \\ Correspondence: Kevin Daly, School of Business, University of Western Sydney, Sydney, Australia. E-mail: \\ K.Daly@uws.edu.au
}

Received: December 5, 2012

Accepted: April 3, 2013

Online Published: April 24, 2013

doi:10.5539/ijef.v5n5p171

URL: http://dx.doi.org/10.5539/ijef.v5n5p171

\begin{abstract}
This paper investigates the transmission mechanism of the Global Financial Crisis originated in the United States to the East Asian equity markets, including the developed markets (Hong Kong, Japan and Singapore), emerging markets (Malaysia, Thailand and Taiwan) and frontier market (Vietnam). To test for the transmission, we employ the constant conditional correlation (CCC) and the dynamic conditional correlation (DCC) based on the MGARCH model to estimate the time-varying correlations between the United States and East Asian equity markets. Our empirical findings suggest that the Global Financial Crisis transmitted to these markets vary over time, particularly to Hong Kong and Singapore during the pre-crisis period, and to Japan and Vietnam during the crisis period. In addition, the results show that almost all the East Asian markets reveal higher correlations to other markets in the region than the United States even during the crisis period. Finally, the crisis is attributed to enhancing the correlations between the frontier market towards regional and global markets.
\end{abstract}

Keywords: global financial crisis, East Asian equity markets, contagion effect, conditional correlation

\section{Introduction}

The Global Financial Crisis (GFC) has been considered as the most severe crisis in history since the 1930s Great Depression. It was attributed to a series of severe market events such as speculative bubble in the U.S. housing market in 2006, the sub-prime mortgage crisis in the United States in early 2007 and the liquidity crunch in global credit markets in mid-2007. The crisis intensified in the second half of 2008 after the U.S. State Bank and Government refused to rescue Lehman Brother's and confirmed the collapse of the American International Group. These events partly caused panic for both investors and financial institutions in the world, leading to a sharp decline in global equity markets which lasted until the first quarter of 2009 (Bartram \& Bodnar, 2009; Dooley \& Hutchison, 2009). For a full comprehensive review of the history of the GFC refer to the study by Arestis; Sobreira and Oreiro (2011).

The above studies focused on the impacts of the GFC for advanced and emerging markets, rather than small young emerging markets. Research documenting the impacts of the GFC at the country, regional and global markets has been performed by Dooley \& Hutchison (2009), Markwat, Kole, \& van Dijk (2009), Bartram and Bodnar (2009), Claessens, Claessens et al., (2010) and Allen \& Carletti (2010)). In addition, several studies indicate that the GFC was more serious than previous crises. For example Gklezakou and Mylonakis (2010), show that while previous crises disturbed the financial systems of directly affected economies, the GFC penetrated practically every aspect of global economic activities. Recently, Guo, Chen and Huang (2011) examined the impacts of the GFC on various markets such as stock, real estate, energy markets and credit default swap markets they find that credit default swaps are non-existent in other crises.

Despite increasing concerns over the direct impacts of the GFC, the issue of how the GFC was transmitted to the global markets has not been widely developed in the literature. Several previous studies, such as Claessens et al. (2010) and Mishkin (2011) examine the transmission of the GFC to the global markets by visually describing the interactions of market movements during the crisis. Other studies explore the transmission mechanism empirically (see, for example Gupta and Donleavy (2009), Naoui; Liouane and Brahim (2010), Marcal et al.(2011) and Kenourgios; Samitas and Paltalidis (2011)); however, almost these studies focus on the impacts of 
the GFC for developed and emerging markets which maintain strong links to the United States. As such, the primary objective of this paper is to empirically explore transmission mechanism of the GFC to equity markets of the East Asian region.

In this paper, we investigate the transmission mechanism of the shock caused by the GFC to equity markets in the East Asian region, including the developed markets (Hong Kong, Japan, Singapore), emerging markets (Malaysia, Thailand, Taiwan) and the frontier market of Vietnam (Note 1). There are two main reasons for selecting these markets. Firstly, the East Asian region has experienced the highest average growth rate in terms of real GDP in the last two decades and has been responsible for the majority of growth recorded globally. Secondly, the region was severely affected by previous 1997 Asian Financial Crisis, in this respect we compare how the region responded to the GFC compared to the 1997 crisis. The data used in the paper is sourced from the DataStream for the period from 1/7/2007 to 31/12/2010. The rest of the paper is structured as follows. Section 2 presents the literature review on crises and transmission mechanisms of crises. Section 3 introduces data and research methods used in the paper. Section 4 discusses empirical findings. Section 5 concludes the paper.

\section{Literature Review}

Over recent decades, global markets have experienced a series of crises that originated in a specific market and rapidly transmitted to other markets. Such transmission of financial turmoil across markets is often refereed as a 'contagion effect' (Dornbusch, Park, \& Claessens, 2000; Forbes \& Rigobon, 2002; Guo, et al., 2011; Khalid \& Kawai, 2003). A study by Claessens and Forbes (2001) indicates that the concept was firstly introduced in chemistry with reference to the spread of medical diseases; however, in the late 1990s, the concept was widely used in the economics to describe a transmission of a shock across markets. There are several definitions of contagion in the existing literature. For instance, while Forbes and Rigobon (2002) define contagion as a significant increase in the correlation between equity markets during a crisis; Claessens, Dornbusch and Park (2010) use the term contagion when describing an increase in a cross market linkage after a shock to one country rather than only a strong linkage between countries.

The World Bank classifies levels of contagion by proposing three definitions (Billio \& Pelizzon, 2003; Claessens $\&$ Forbes, 2001). The first definition is very broad defining contagion as a cross-country transmission of shocks or cross-country spillover effects; however, this definition takes into consideration transmission of shocks in both tranquil and crisis periods. The second definition is restrictive stating that contagion is the transmission or co-movement of shocks in excess of what can be explained by economic fundamentals. This definition is claimed as the most controversial one in order to identify the underlying fundamentals. The third definition is known as very restrictive definition emphasizing a transmission mechanism of a shock among countries during a period of crisis. This definition is similar to a 'shift contagion' given by Forbes and Rigobon (2002) defining contagion as a significant increase in cross-market linkages after a shock to a specific market and is widely used in the literature (see for example Kuper and Lestano (2007); Gupta and Donleavy (2009); Yiu, Alex-Ho and Choi (2010); Yu, Fung and Tam (2010). In the paper, we utilize the shift contagion definition to examine the propagation of transmissions of the shock caused by the GFC to East Asian equity markets.

Contagion effects can generally be explained by two main sources. In early studies, international trade and financial linkages and common shocks are often used to provide thoughtful explanations for the transmission mechanism of contagion (Kearney, 2000; Phylaktis \& Ravazzolo, 2002; Pretorius, 2002). However, as many crises occurred more frequently in recent decades, empirical results find much evidence of transmissions of a shock from one country to other countries that do not have close fundamental linkages to a host country. As such, another source of contagion associated with investor behavior is suggested. Khalid and Kawai (2003), for instance, document three sources of contagion, namely common shocks, financial linkages and shifts in investors' sentiments. Dornbusch, Park and Claessens (2000) discuss two sources of contagion effect over turbulence periods. The first source is related to fundamental-based channels associated with real and financial linkages across borders, while the second is attributed from irrational behaviors of investors resulting from liquidity problems, imperfect information, and multiple equilibria. A similar viewpoint employs investor behavior to explain for the spillover of shocks across markets can be found in studies by Claessens and Forbes (2001), Karolyi (2003) and Caramazza; Ricci and Salgado (2004).

Equity market linkage refers to an interaction among equity markets through which investors can optimize their risk-adjusted returns by diversifying their investment portfolios across markets. The concept is based on two foundational theories. The first one is the Purchasing Power Parity Theory positing that relative prices of identical goods should be in equilibrium to represent their purchasing power across markets (Brooks 2002; Del Bianco 2008; Korap and Aslan 2010). The second theory is the Modern Portfolio Theory which states important 
roles of risks, returns, and correlations in constructing investment portfolios of investors and suggests that investors may get higher returns if they diversify internationally (Elton and Gruber 1997; Gklezakou and Mylonakis 2010). Although both of these theories are based on a number of simplifying assumptions, they remain the cornerstones of modern finance in asset management.

In the existing literature, equity market linkages have been mainly identified under three headings; namely co-integration, causality and contagion depending on the nature of linkages. Co-integration and causality describe fundamental linkages among equity markets which are known as a long-run and short-run linkage, respectively. Contagion relates to a transmission mechanism of a shock among equity markets during periods of crisis by capturing a significant increase in correlations of market volatilities (Note 2) (Forbes and Rigobon 2002; Corsetti, Pericoli and Sbracia 2005). These three linkages overall represent a comprehensive picture on cross-market linkages.

In early studies focused on global equity market linkages most researchers explain sources of linkages with regard to fundamental-based linkages, for example trade and finance links (Kearney 2000; Phylaktis and Ravazzolo 2002; Pretorius 2002; Khalid and Kawai 2003). However, in the 1990s as global markets experienced a series of crises, other sources of linkages - known as irrational linkages - emerged such as imperfect information, investor sentiment, and multiple equilibrium (Note 3) (Dornbusch, Park and Claessens 2000; Karolyi 2003).

Recently, several researchers document limitations of modern finance theories in the real world, particularly in a context of financial crises, as correlations of global equity markets appear to increase (Cheung, Fung and Tsai 2010; Chakrabarti 2011). Thus, an understanding of equity market linkages during periods of crises is of interest to researchers and practitioners. Due to the severity and ample effects of the GFC, a large number of studies examine impacts of the GFC on advanced and major emerging markets that have strong links with the United States rather than small and young equity markets. Therefore, the primary objective of this paper is to explore the impacts of the GFC of a small and young emerging market and on its linkages to global equity markets.

\section{Data and Methodology}

\subsection{Data Collection}

In order to investigate the transmission of the GFC to the East Asian equity markets, the paper employs time series data consisting of the daily closing prices of seven market indices in the region including the Hang Seng Index for Hong Kong, the TSE Composite Index for Taiwan, the Strait Times Index for Singapore, the Nikkei 225 Stock Average for Japan, the KLSE Composite Index for Malaysia, the SET Index for Thailand and the VN-Index for Vietnam. The S\&P 500 Composite index of the United States is employed to take into account the transmission of the GFC to the region. According to the market classification of the MSCI (2012), we separate the seven East Asian market indices in the sample into three groups. The developed market group includes Hong Kong, Japan and Singapore. The emerging market group covers Malaysia, Taiwan and Thailand, and the frontier market includes Vietnam. The data is sourced from the DataStream International for the period from 1/7/2007 to $31 / 12 / 2010$. On non-trading days of the market indices, we assume to stay the same compared to the previous trading day. In addition, the market indices in local currency are used to capture influences of local economic policy and economic conditions on market linkages.

It is notable that the trading hours of Asian markets are overlapping while those of the United States equity market are one day lagged. Hence, in this paper, the equity market returns of the United States are lagged one day compared to that of the other series data. The first differences of logarithms of market indices multiplied by 100 are constructed to measure market returns of the selected markets.

For capturing the transmission of the GFC to the selected markets, we separate the period of study into sub-periods according to the descriptions by Mishkin (2011) and Ait-Sahalia et al (2012). Particularly, the period of study is divided into three sub-periods. The pre-crisis period is from 1/7/2007 to 14/9/2008 comprising 315 observation of each series. The crisis period is from 15/9/2008 to 31/3/2009 comprising 142 observations of each series, and the post-crisis period starts on 1/4/2009 and ends on 31/12/2010 comprising 458 observations of each series

The descriptive statistics of the market returns over the sub-periods are shown in Table 1. In general, we can see some similar findings during the pre-crisis and crisis period. More specifically, all the markets have negative average rate of returns over the two periods implying declines of the market levels of the entire markets. It can be explained by the severity and ample effects of the sub-prime crisis and the GFC on the regional markets. Interestingly, the Vietnam index recorded the highest negative returns over the periods implying the strongest 
impacts of the crises on the frontier market compared to the other markets in the sample. In the meantime, the Hong Kong equity market experience the highest standard deviation of market returns suggesting a high vulnerability of the market during the periods. It is notable that the higher standard deviations of developed markets relative to those of the emerging and frontier markets during the crisis period imply considerable influences of the GFC on the developed markets in the region.

During the post-crisis period, all the markets record positive average rates of return reflecting the recovery of the markets after the GFC; however, the pattern of recovery varies different within the region. The highest return is for the Taiwan index (0.19) while the lowest is for the Japan index (0.05). It suggests a weak recovery of Japan compared to the other markets. It could be due to its high dependence on the export of advanced manufacturing products. In addition, the skewness reveals some negative but some positive values over the three periods implying that market returns sometime change from the long right tail to left right tail and vise versa over the sub-periods. The high kurtosis values suggest the peak distributions of market returns.

During the pre-crisis period, the correlations between developed markets appear to be higher than between emerging markets. The highest correlation is found between Singapore and Hong Kong (0.79) and the lowest correlation is between Singapore and Vietnam (-0.02). The strong relationship between Singapore and Hong Kong can be explained by their close trading linkages in the long run. In addition, the Vietnam equity market reveals the lowest correlations with both the emerging and developed markets in the sample suggesting a quite isolated relationship of the market towards the regional and global markets. The United States reveals the highest correlations with Japan (0.53) and Singapore (0.51) while the lowest correlation exists with Vietnam (0.07).

Table 2 shows the correlation coefficients of market returns between the equity markets. Overall, the table almost shows higher correlations amongst the markets during the crisis period compared to the pre- and post-crisis period impling strong vulnerable of the East Asian equity markets during the GFC.

Table 1. Descriptive statistics of market returns

\begin{tabular}{|c|c|c|c|c|}
\hline \multicolumn{5}{|c|}{ Pre-crisis period (from $1 / 7 / 2007$ to $14 / 8 / 2008$ ) } \\
\hline & Mean & Std. Dev. & Skew & Kurtosis \\
\hline US & -0.06 & 1.29 & -0.06 & 3.4 \\
\hline HK & -0.04 & 2.16 & 0.03 & 5.24 \\
\hline JP & -0.13 & 1.6 & -0.26 & 3.82 \\
\hline SG & -0.1 & 1.55 & 0 & 4.34 \\
\hline ML & -0.08 & 1.2 & -1.84 & 17.71 \\
\hline TW & -0.05 & 1.37 & 0.24 & 3.75 \\
\hline TL & -0.11 & 1.72 & -0.29 & 3.93 \\
\hline $\mathrm{VN}$ & -0.24 & 1.8 & 0.02 & 3.21 \\
\hline \multicolumn{5}{|c|}{ Crisis period (from $15 / 9 / 2008$ to $31 / 3 / 2009$ ) } \\
\hline US & -0.32 & 3.54 & 0.12 & 3.71 \\
\hline HK & -0.25 & 3.78 & 0.28 & 5.02 \\
\hline JP & -0.29 & 3.62 & -0.14 & 4.94 \\
\hline SG & -0.29 & 2.69 & 0.06 & 3.83 \\
\hline ML & -0.13 & 1.23 & 0.14 & 4.57 \\
\hline TW & -0.29 & 2.59 & -0.76 & 6.61 \\
\hline $\mathrm{TL}$ & -0.13 & 2.28 & -0.17 & 3.42 \\
\hline $\mathrm{VN}$ & -0.37 & 2.33 & 0.09 & 2.38 \\
\hline \multicolumn{5}{|c|}{ Post-crisis period (from $1 / 4 / 2009$ to $31 / 12 / 2010$ ) } \\
\hline US & 0.1 & 1.19 & -0.23 & 4.48 \\
\hline HK & 0.12 & 1.46 & 0.33 & 4.66 \\
\hline JP & 0.05 & 1.35 & -0.01 & 3.47 \\
\hline SG & 0.14 & 1.13 & 0.57 & 6.24 \\
\hline ML & 0.12 & 0.62 & 0.31 & 4.63 \\
\hline TW & 0.19 & 1.28 & -0.27 & 4.91 \\
\hline $\mathrm{TL}$ & 0.12 & 1.21 & -0.06 & 6.38 \\
\hline $\mathrm{VN}$ & 0.12 & 1.76 & -0.08 & 3.41 \\
\hline
\end{tabular}

During the crisis, almost all correlations increased considerably, particularly the correlations between the equity markets of East Asia. The correlations between the advanced markets and emerging markets in the region span 
from 0.5 (Thailand and Taiwan) to 0.78 (Singapore and Hong Kong) implying that these markets move in similar patterns in this period. Notably, the correlations between the Vietnam and other markets under investigation considerably increase, particularly with the United States $(0.55)$ and Japan (0.47). This result implies a strong influence of the GFC on the Vietnam equity market which may enhance its linkages to global equity markets. Notably that among the East Asian markets, only Japan and Vietnam report impressively stronger correlations with the United States while almost other markets reveal weaker interactions. The findings may suggest different influences of the shock to the United States on the East Asian equity markets.

Table 2. Correlation coefficient of market returns

\begin{tabular}{|c|c|c|c|c|c|c|c|c|}
\hline & US & HK & JP & SG & ML & $\mathrm{TL}$ & TW & $\mathrm{VN}$ \\
\hline \multicolumn{9}{|c|}{ Pre-crisis period (from 1/7/2007 to $14 / 8 / 2008$ ) } \\
\hline US & 1 & & & & & & & \\
\hline HK & 0.49 & 1 & & & & & & \\
\hline JP & 0.53 & 0.66 & 1 & & & & & \\
\hline SG & 0.51 & 0.79 & 0.67 & 1 & & & & \\
\hline ML & 0.43 & 0.50 & 0.48 & 0.57 & 1 & & & \\
\hline $\mathrm{TL}$ & 0.35 & 0.54 & 0.42 & 0.57 & 0.48 & 1 & & \\
\hline TW & 0.43 & 0.57 & 0.59 & 0.60 & 0.50 & 0.49 & 1 & \\
\hline $\mathrm{VN}$ & 0.07 & 0.04 & 0.08 & -0.02 & 0.00 & 0.00 & 0.00 & 1 \\
\hline \multicolumn{9}{|c|}{ Crisis period (from $15 / 9 / 2008$ to $31 / 3 / 2009$ ) } \\
\hline US & 1 & & & & & & & \\
\hline HK & 0.37 & 1 & & & & & & \\
\hline JP & 0.65 & 0.68 & 1 & & & & & \\
\hline SG & 0.30 & 0.78 & 0.60 & 1 & & & & \\
\hline ML & 0.37 & 0.54 & 0.56 & 0.67 & 1 & & & \\
\hline $\mathrm{TL}$ & 0.26 & 0.69 & 0.56 & 0.70 & 0.59 & 1 & & \\
\hline TW & 0.45 & 0.63 & 0.65 & 0.58 & 0.60 & 0.50 & 1 & \\
\hline $\mathrm{VN}$ & 0.55 & 0.24 & 0.47 & 0.22 & 0.34 & 0.36 & 0.36 & 1 \\
\hline \multicolumn{9}{|c|}{ Post-crisis period (from $1 / 4 / 2009$ to $31 / 12 / 2010$ ) } \\
\hline US & 1 & & & & & & & \\
\hline HK & 0.38 & 1 & & & & & & \\
\hline $\mathrm{JP}$ & 0.55 & 0.57 & 1 & & & & & \\
\hline SG & 0.33 & 0.75 & 0.49 & 1 & & & & \\
\hline ML & 0.42 & 0.55 & 0.46 & 0.57 & 1 & & & \\
\hline $\mathrm{TL}$ & 0.23 & 0.55 & 0.37 & 0.54 & 0.43 & 1 & & \\
\hline TW & 0.38 & 0.60 & 0.53 & 0.60 & 0.50 & 0.36 & 1 & \\
\hline $\mathrm{VN}$ & 0.33 & 0.18 & 0.21 & 0.15 & 0.18 & 0.10 & 0.16 & 1 \\
\hline
\end{tabular}

During the post-crisis period, the correlations among the markets appear to decline slightly with the exception of the Vietnam equity market which reports higher correlations with the other markets during the post-crisis period in comparison to those during the pre-crisis period. In addition, despite the slight decline, the United States remains the highest correlations with Japan (0.55) compared to the other markets in the region. It is notable that almost all the equity markets in the East Asian region reveal their highest correlations with Hong Kong and Singapore. It highlights considerable influences of the two markets in the region.

To visually inspect the volatilities of the selected markets over time, we plot the movements of the daily market returns of the eight markets over the period of 2007 - 2010. In general, the markets are relatively stable before the crisis, but appear to be highly volatile during the crisis. As we can see in Figure 1, the United States, Hong Kong and Japan are more volatile than the other markets because their volatilities span from -15 to +15 ; while those of other markets range from -10 to +10 . In addition, Malaysia is likely to be less influenced by the GFC except for a sharp drop in the first quarter of 2008 implying the quick response of the Malaysia Government to get rid of the crisis. Notably although that there is no dramatic drop in the market volatilites of Vietnam, the market is clearly impacted negatively over the crisis. This could be explained by strict controls of the Vietnamese Governments in supervising and managing the market, such as the narrow daily price-limit change regulation and a maximum proportion of foreign ownership of listing firms allowed to participate in the market. 

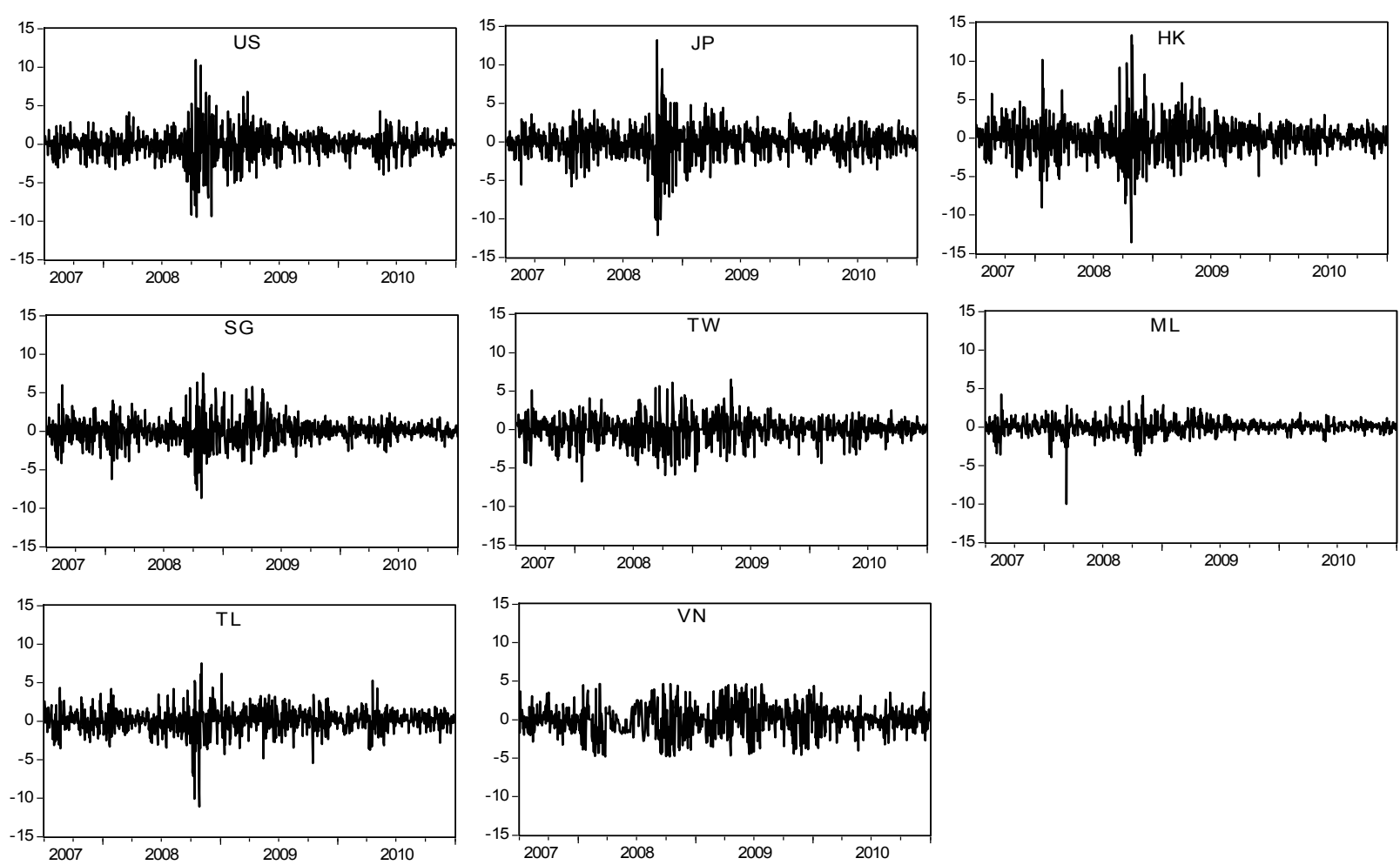

Figure 1. Movements of market returns

It be may concluded that due to differences in size and structure, the influences of the GFC on the East Asian equity markets be analysed as a exceptional case rather than following the general global pattern. However, when and where the GFC transmitted to the markets in the region cannot be determined by descriptive analysis. As such, other research approachs will be conducted to explore the transmission mechanism.

\subsection{Research Methodology}

In this paper, we investigate the transmission of a shock caused by the GFC to the East Asian markets by conducting empirical tests with regard to the existence of contagion effects across markets. As mentioned above, we follow the very strict definition of contagion as a significant increase in cross-market linkages after a shock or crisis. As such, we examine the contagion effect by measuring cross-market correlations. However, as discussed by Forbes and Rigobon (2002), a correlation between two markets is time-varying and conditional on market volatilities, particularly during a turbulent period because the correlation may be biased by increases of market volatilities. Hence, two models of time-varying correlations are used in the paper. The first model is the constant conditional correlation (CCC) suggested by Bollerslev (1990) and the second model is the time-varying dynamic conditional correlation (DCC) proposed by Engle (2002). These empirical methods estimate the dynamic of time-varying correlations tracking from multivariate generalized autoregressive conditional heteroskedasticity (MGARCH) model.

Specifically, to capture the time-varying variances of market returns, the univariate generalized autoregressive conditional heteroskedasticity model, GARCH $(1,1)$ suggested by Bollerslev (1986) is firstly employed to estimate conditional return and conditional variance of individual market returns. The equations are given as follows:

Returns equation

$$
r_{t}=\mu+\varepsilon
$$

Volatility equation

$$
h_{t}=w_{i}+\alpha \varepsilon_{i . t-1}^{2}+\beta h_{i t-1}
$$

where $i=1,2 \ldots \mathrm{m}$ indicate the ith equation in the model. $r_{t}$ is a linear regression of individual market returns equation including a constant term $\mu$ and the error term $\varepsilon_{\mathrm{i} . \mathrm{t}-1}$ of the ith equation. The conditional variance, $\mathrm{h}_{\mathrm{i} . \mathrm{t}}$, is a function of lagged values of square residuals $\varepsilon_{\mathrm{i} . \mathrm{t}-1}^{2} \cdot \alpha$ captures innovations of its past square residuals 
while $\beta$ present influences of lagged values of its conditional variance. $w_{i}$ is a constant term of the volatility equation. The necessary conditions to the equation (2) are both $\alpha$ and $\beta$ are nonnegative and $\alpha+\beta<1$.

After estimating the volatilites of individual markets in the sample, we measure the CCC between pairs of the markets. The constant conditional correlation $\left(\rho_{t}\right)$ is decomposed into a matrix of conditional variance $\left(h_{i j}\right)$ and a diagonal matrix of the square root of the conditional variances $\left(\mathrm{h}_{\mathrm{i} i, \mathrm{t}}^{-1 / 2}\right)$ by using the following model

$$
\rho_{t}=h_{i i, t}^{-1 / 2} h_{i j, t} h_{j j, t}^{-1 / 2}
$$

The CCCs are estimated in the paper over the pre-crisis, crisis and post-crisis periods. If the CCC significantly changes over the crisis and post-crisis period compared to that over the pre-crisis period, this coutome leads supports for the transmission of the GFC from the United States to the other markets. If the CCC is not significant over the crisis and post-crisis period compared to the pre-crisis period, we conclude that no transmission of a shock occurs. In case the CCC maintains the high values over the sub-period, a conclusion of interdependence between the markets is suggested.

Although the CCC model measures the conditional correlations of market volatilities; however, the correlations are static over our period of study. As such, we further employ the DCC model that allows for time-varying conditional correlation. This model is also firstly based on the univariate GARCH $(1,1)$ model of market returns of individual markets to estimate their conditional variances $\sigma_{t}$. Each univariate error process is then transformed to the standardized residuals by

$$
\delta_{t-1}=\frac{\varepsilon}{\sqrt{h_{t}}}
$$

The conditional variance is assumed to be time varying by following the GARCH $(1,1)$ model given by

$$
\sigma_{i j, t}=\left(1-\theta_{1}-\theta_{2}\right) \bar{\sigma}_{i j}+\theta_{1} \delta_{t-1} \delta_{t-1}^{\prime}+\theta_{2} \sigma_{i j, t-1}
$$

where $\bar{\sigma}$ is the unconditional covariance of the standardized residuals $\left(\delta_{t}\right)$ resulting from the univariate GARCH, and $\theta_{1}$ and $\theta_{2}$ are parameters. Both $\theta_{1}$ and $\theta_{2}$ must be positive and $\theta_{1}+\theta_{2}<1$. In other words, the DCC model includes the two GARCH $(1,1)$ processes of stock returns and standardized residuals. The DCC is decomposed into a matrix of conditional variance $\left(\sigma_{\mathrm{ij}}\right)$ and a diagonal matrix of the square root of the conditional variances $\left(\sigma_{\mathrm{ii}, \mathrm{t}}^{-1 / 2}\right)$ is given below

$$
\rho_{t}=\sigma_{i i, t}^{-1 / 2} \sigma_{i j, t} \sigma_{j j, t}^{-1 / 2}
$$

To measure the coefficients, Engle (2002) proposes to maximize the likelihood function in the following equation

$$
L_{t}=-\frac{1}{2} \sum_{t=1}^{T}\left[n \log (2 \pi)+\log \left|D_{t}\right|^{2}+\varepsilon_{t}^{\prime} D_{t}^{-2} \varepsilon_{t}\right]--\frac{1}{2} \sum_{t=1}^{T}\left[\log \left|R_{t}\right|+\varepsilon_{t}^{\prime} R_{t}^{-1} \varepsilon_{t}-\varepsilon_{t}^{\prime} \varepsilon_{t}\right]
$$

The results of DCC tests are plotted in the seven graphs presenting the time-varying conditional correlations between the United States and other markets in the sample over the period from 1/7/2007 to 31/12/2010. The $M A T L A B$ package is used to perform these tests.

\section{Empirical Results}

\subsection{Volatilities of Individual Market}

In order to estimate the conditional correlations of a pair of equity market volatilities, we firstly conduct the univariate $\operatorname{GARCH}(1,1)$ model for individual markets to estimate individual market volatility series. As we can be seen in Table 3, almost all of the parameters are statistically significant this result supports using the CCC and DCC models to investigate the transmission of shock among the markets. In addition, the sum of parameters in the volatility equation nearly equals to one, implying that the market volatilities highly measure the behavior of each market. There are some parameters, however which appear insignificant during the crisis period. This can be explained by the shorter period of study of the crisis period (142 observations) compared to the pre-crisis period (315 observations) and the post-crisis period (458 observations). It is notable that during the crisis period, the market volatilities of the Vietnam equity market cannot be measured effectively by its owns residuals and its lagged values because all the parametters are insignificant. This result add caution in interpreting empirical findings on the conditional correlations between the Vietnam and United States equity markets during the crisis period. 
Table 3. Results of the volatility equations of individual market returns

\begin{tabular}{|c|c|c|c|c|}
\hline Market & Coefficient & Pre-crisis (315 obs) & Crisis (142 obs) & Post-crisis (458 obs) \\
\hline \multirow[t]{3}{*}{ US } & $\mathrm{ARCH}$ & $0.03 * *$ & $0.08 * * *$ & $0.10^{* *}$ \\
\hline & GARCH & 0.87 & $0.89 * * *$ & $0.89 * *$ \\
\hline & constant & 0.17 & 0.34 & $0.02 * *$ \\
\hline \multirow[t]{3}{*}{ HK } & $\mathrm{ARCH}$ & $0.16^{* *}$ & $0.13 * * *$ & $0.03 * *$ \\
\hline & GARCH & $0.76^{* * *}$ & $0.83 * * *$ & $0.96^{* *}$ \\
\hline & constant & 0.40 & 0.57 & $0.01 * *$ \\
\hline \multirow[t]{3}{*}{ JP } & $\mathrm{ARCH}$ & $0.08^{* *}$ & $0.19 * * *$ & $0.05^{* *}$ \\
\hline & GARCH & $0.86^{* * *}$ & $0.77 * * *$ & $0.91^{* * *}$ \\
\hline & constant & $0.15 * * *$ & 0.56 & $0.07 * * *$ \\
\hline \multirow[t]{3}{*}{ SG } & $\mathrm{ARCH}$ & $0.14 * *$ & $0.08^{* *}$ & $0.08^{* *}$ \\
\hline & GARCH & $0.78 * * *$ & $0.86^{* * *}$ & $0.90 * *$ \\
\hline & constant & 0.21 & 0.40 & $0.02 * *$ \\
\hline \multirow[t]{3}{*}{ ML } & $\mathrm{ARCH}$ & $0.24 * * *$ & $0.12 * * *$ & $0.18^{* *}$ \\
\hline & GARCH & $0.72 * * *$ & 0.76 & $0.68^{* * *}$ \\
\hline & constant & $0.11 * * *$ & 0.18 & $0.05^{* *}$ \\
\hline \multirow[t]{3}{*}{ TL } & $\mathrm{ARCH}$ & $0.15 * * *$ & $0.06^{* *}$ & $0.10^{* *}$ \\
\hline & GARCH & $0.79 * * *$ & $0.92^{* *}$ & $0.87 * *$ \\
\hline & constant & $0.13 * * *$ & $0.04 * * *$ & $0.04 * *$ \\
\hline \multirow[t]{3}{*}{ TW } & $\mathrm{ARCH}$ & $0.10^{* *}$ & $0.05 * * *$ & $0.07 * *$ \\
\hline & GARCH & $0.82 * * *$ & 0.16 & $0.91 * *$ \\
\hline & constant & 0.24 & 4.58 & $0.03 * *$ \\
\hline \multirow[t]{3}{*}{$\mathrm{VN}$} & $\mathrm{ARCH}$ & $0.31 * * *$ & 0.21 & $0.14^{* *}$ \\
\hline & GARCH & $0.62 * * *$ & 0.77 & $0.84 * *$ \\
\hline & constant & 0.28 & 0.16 & $0.07 * *$ \\
\hline
\end{tabular}

Notes: $* * *, * *$ indicate statistical significance at $1 \%, 5 \%$ and $10 \%$, respectively.

\subsection{Constant Conditional Correlation}

Table 4 presents the empirical estimations of the CCC-MGARCH(1,1) models. The results show not only the conditional correlation on market volatility between the United States and other markets but also those between the pairs of other markets

Over the pre-crisis period, the market volatility of the United States reveal high correlations with the developed markets rather than the emerging and frontier markets, while the regional markets reveal the higher conditional correlations with both Hong Kong and Singapore. It implies significant roles of Hong Kong and Singapore in the region in the region. The volatility of the Vietnam equity market is quite small suggesting for the less influences of the regional markets toward the Vietnam.

During the crisis, the United States reveals a significant increase in the conditional correlation with the Japan market, followed by Vietnam, Taiwan and Hong Kong. It implies that Japan is likely to be the first market in the region affected by the crisis. However, it may be surprising that the CCCs between the United States equity market and the East Asian equity markets do not increase except for those of the Japan and Vietnam. It is in line with our findings in the unconditional correlations among the markets. It may suggest that the contagion effect from the United States to the regional markets is not apparently. In addition, all the correlations of market volatility of the Vietnam market are reported to be significantly higher during the GFC than before the GFC giving implications on a sensitive characterize of the frontier market towards the shock originated in the United States. Interestingly, our findings reports that the Thailand equity market is less directly influenced by the GFC during the GFC as its conditional correlation of market volatility declines relative to that of the pre-crisis period. The fluctuation of the Thailand equity market over the crisis period may result from the volatilities of regional markets such as Hong Kong and Singapore.

Over the post-GFC, the conditional correlations of almost markets turn back relatively to the correlations during the pre-GFC. The market volatilities of both the Hong Kong and Singapore market still prominently influence the other markets in the region. The volatilities of the Japan market reveal the highest close linkage to the volatilities of the United States market. Importantly, we find significant increases in the conditional correlations between the Vietnam and both the United States and regional markets. It gives implications on significant 
influences of the shock caused by the GFC on the frontier market.

In summary, we may conclude that the CCCs results suggest that the markets of East Asia are closely connected during the crisis period. The transmission of the shock originated from the United States which quickly transferred to Japan and Vietnam rather than other countries. This suggests that the shock by the GFC originated from the United States may transmit to the East Asian equity market via Japan.

Table 4. Constant conditional correlation of market volatilities

\begin{tabular}{|c|c|c|c|c|c|c|c|c|}
\hline & US & HK & JP & SG & ML & TL & TW & $\mathrm{VN}$ \\
\hline \multicolumn{9}{|c|}{ Pre-crisis period (from $1 / 7 / 2007$ to $14 / 8 / 2008$ ) } \\
\hline US & 1 & & & & & & & \\
\hline HK & 0.52 & 1 & & & & & & \\
\hline JP & 0.53 & 0.64 & 1 & & & & & \\
\hline SG & 0.52 & 0.79 & 0.65 & 1 & & & & \\
\hline ML & 0.43 & 0.51 & 0.43 & 0.55 & 1 & & & \\
\hline $\mathrm{TL}$ & 0.35 & 0.54 & 0.43 & 0.54 & 0.45 & 1 & & \\
\hline TW & 0.43 & 0.60 & 0.59 & 0.60 & 0.47 & 0.47 & 1 & \\
\hline $\mathrm{VN}$ & 0.12 & 0.09 & 0.11 & 0.04 & 0.04 & 0.03 & 0.06 & 1 \\
\hline
\end{tabular}

\begin{tabular}{|c|c|c|c|c|c|c|c|c|}
\hline \multicolumn{9}{|c|}{ Crisis period (from $15 / 9 / 2008$ to $31 / 3 / 2009$ ) } \\
\hline US & 1 & & & & & & & \\
\hline HK & 0.43 & 1 & & & & & & \\
\hline JP & 0.66 & 0.66 & 1 & & & & & \\
\hline SG & 0.30 & 0.76 & 0.59 & 1 & & & & \\
\hline ML & 0.36 & 0.58 & 0.58 & 0.65 & 1 & & & \\
\hline $\mathrm{TL}$ & 0.28 & 0.67 & 0.58 & 0.71 & 0.60 & 1 & & \\
\hline TW & 0.43 & 0.65 & 0.70 & 0.59 & 0.60 & 0.52 & 1 & \\
\hline $\mathrm{VN}$ & 0.52 & 0.22 & 0.44 & 0.19 & 0.30 & 0.30 & 0.33 & 1 \\
\hline \multicolumn{9}{|c|}{ Post-crisis period (from $1 / 4 / 2009$ to $31 / 12 / 2010$ ) } \\
\hline US & 1 & & & & & & & \\
\hline HK & 0.41 & 1 & & & & & & \\
\hline JP & 0.54 & 0.57 & 1 & & & & & \\
\hline SG & 0.35 & 0.72 & 0.49 & 1 & & & & \\
\hline ML & 0.44 & 0.52 & 0.45 & 0.56 & 1 & & & \\
\hline $\mathrm{TL}$ & 0.23 & 0.51 & 0.36 & 0.51 & 0.39 & 1 & & \\
\hline TW & 0.39 & 0.60 & 0.55 & 0.58 & 0.46 & 0.35 & 1 & \\
\hline $\mathrm{VN}$ & 0.34 & 0.19 & 0.23 & 0.12 & 0.19 & 0.08 & 0.17 & 1 \\
\hline
\end{tabular}

\subsection{Dynamic Conditional Correlation}

As indicated by Corsetti, Pericoli and Sbracia (2005), a correlation between two market returns is not static but varies over time. As such, in the paper, we capture the time-varying correlations between the United States and the East Asian equity markets. Specifically, we employ the DCC-MGARCH model suggested by Engle (2002) to measure the time-varying conditional correlation coefficients between two markets. The results of the time-varying conditional correlation coefficients between the United States and the East Asian markets are plotted in Figure 2. In general, we can see that the highest volatility of the DCCs is found between the United States and Japan (spanning from 0.35 to 0.67 ) while the lowest volatility of the DCCs is found between the United States-Vietnam (spanning from 0.2 to 0.4 ).

During the pre-GFC, the graphs show a relatively high correlation in the dynamic path of several markets such as Hong Kong, Singapore, Malaysia and Thailand which can be explained by their significant influences by the sub-prime mortgage crisis in the United States. It is also notable that the time-varying conditional correlations of the United States and almost markets decline significantly around January 2008 as some large U.S international corporations reported losses in their performances in 2007. However, the DCCs then recover quickly implying that the negative effects of the sub-prime mortgage crisis do not cause significant impacts on the East Asian equity markets. 

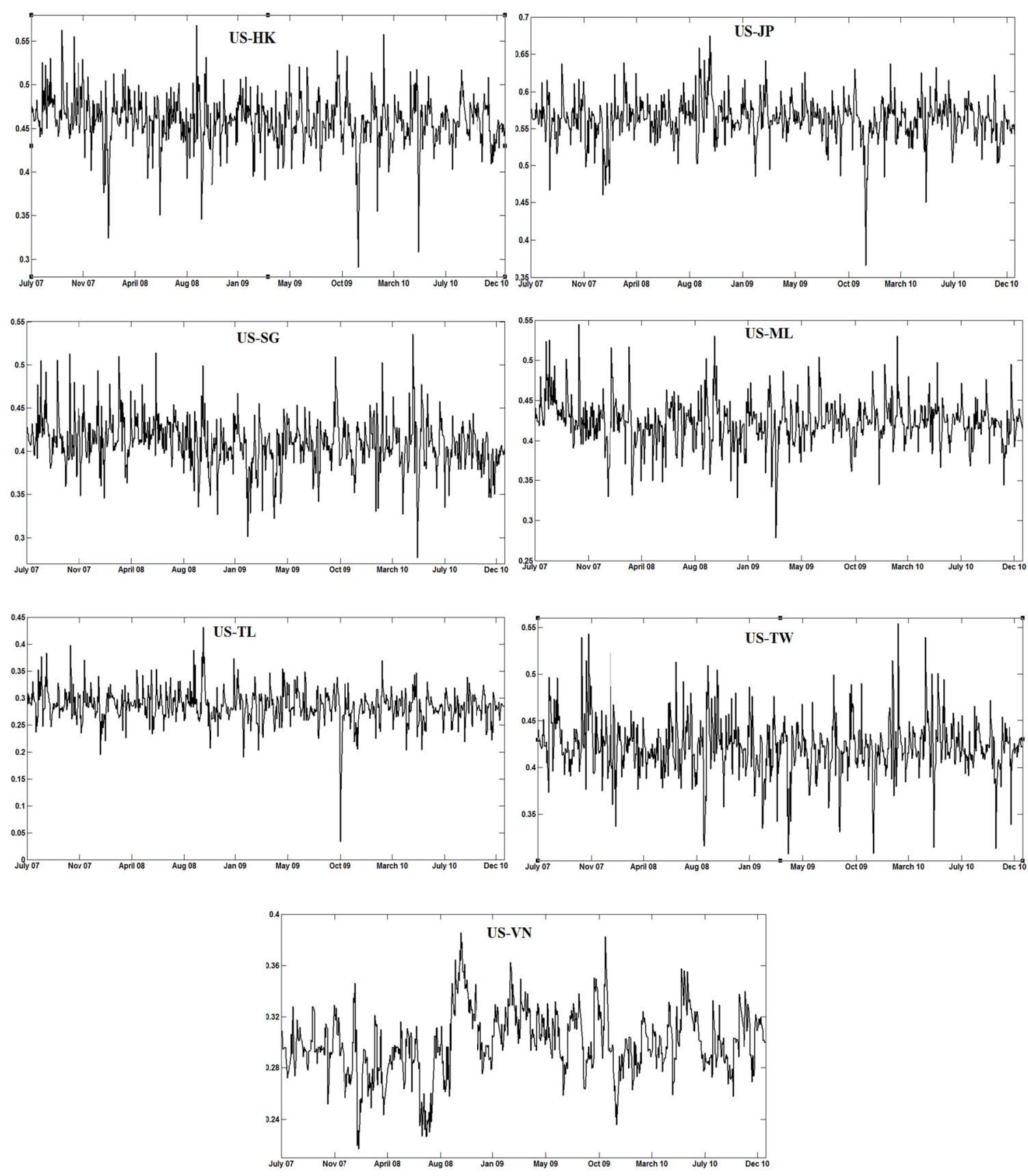

Figure 2. Time-varying dynamic conditional correlations of market volatilities

Figure 2 also shows that the high conditional correlation in the market volatilities of Japan, Hong Kong, Malaysia, Thailand and Vietnam markets over the period from September 2008 to October 2008. It implies for the transmission of the GFC to these markets particularly in September 2008 after the bankruptcy of the Lehman Brother and the collapse of the AIG. Notably that both the DCCs of Singapore and Taiwan do not significantly increase during this period in comparison to the DCC during the pre-crisis period. It can be explained by the fact that the United States is the largest importers of industrial products from Singapore and Taiwan. Hence, these countries are severely affected during the sub-prime mortgage crisis. As such, their responses to over the GFC period are not sharply. Interestingly, the DCCs of the frontier market, Vietnam, significantly increase during the crisis period suggesting strong impacts of the market during the GFC.

It is noteworthy that the influence of the GFC on the East Asian equity markets vary significantly. While many markets reveal the relatively low conditional correlations to the United States around March 2008, the correlation of Hong Kong remains moderate, and that of Vietnam is still high. These results imply the 
transmission of the GFC shock from the United States to the East Asian equity markets during the crisis.

During the post-GFC, the time-varying conditional correlations between the developed and emerging markets in the East Asian region and the United States appear to decline slightly, implying a lesser impact to the shock from the United States. However, the DCCs between the Vietnam and United States market maintain a relatively highe level of interdependence during the post-crisis period compared to those during the pre-crisis period implying stronger correlations between the Vietnam and the United States after the crisis.

In summary, our findings suggest evidence of a transmissions mechanism operating from the United States to the East Asian market. This result is in line with the results by Yiu; Alex-Ho and Choi (2010) and Hwang (2012) who find evidence of contagion between the United States andHong Kong, Japan and Singapore during the period from $9 / 2007$ to $3 / 2009$. However, our findings extends their results by showing that the contagion effect exists between the United State and Hong Kong and Singapore during the subprime crisis. In addition, our results are consistent with a study by Gupta and Guidi (2012) who find evidence of contagion effect from the United States to the equity market of India, as well as a study by Syllignakis and Kouretas (2011) who provide evidence of the transmission of the shock in the United States to the CEE stock returns during the 2007-2009 financial crises.

\section{Conclusion}

This paper employs the constant and dynamic conditional correlation models based on the MGARCH $(1,1)$ to investigate the transmission of the global financial crisis to the developed, emerging and frontier markets in the East Asian region. The models allow us to trace the existance of time-varying correlation of market volatilities between the United States and each of the selected markets. By partitioning the period of study into the pre-crisis, crisis and post-crisis period, we can explore the transmission of the crisis to the East Asian equity market over time.

The empirical findings suggest that among the examined markets, Japan is the most significantly influenced market by the GFC due to its highest correlations with the US markets. In addition, both the Hong Kong and Singapore market are more severely influenced by the sub-prime mortgage crisis in the United State in the mid 2007 rather than the GFC. This result is explained by the close linkages in the international trades because the United States, Hong Kong and Singapore. Furthermore, although the emerging markets in the region are influenced by the shock from the United States over the crisis period; the linkages are more correlated to the developed markets in the region rather than the United States. In addition, the GFC is likely to transmit to the East Asian markets via Japan. Finally, the transmission effects of the GFC to the frontier market Vietnam, is more significant than any other market in the region. The results suggest some implications for policy makers and international fund managers. Firstly, an understanding of the transmission of a shock caused by one market to another markets may give policy makers a clear viewpoint on the linkages between the markets. In the paper, we not only find empirical evidences of the transmission of the shock caused by the United States to the East Asian markets, but also identify specific time periods during which the crisis is transmitted to these markets. Thus, policy makers can understand the relationships between the volatilities of their equity markets and the regional and global markets which may improve the monitoring and supervision of their markets. In addition policy makers may take account of international monetary policies in avoiding the negative impacts from a shock caused by another market. International fund managers can identify the transmission mechanism of shocks to the East Asian markets which inturn may improve their portfolio diversification strategies across equity markets in the region.

\section{References}

Ahlgren, N., \& Antell, J. (2010). Stock market linkages and financial contagion: A cobreaking analysis. Quarterly Review of Economics \& Finance, 50(2), 157-166. http://dx.doi.org/10.1016/j.qref.2009.12.004

Aït-Sahalia, Y., Andritzky, J., Jobst, A., Nowak, S., \& Tamirisa, N. (2012). Market response to policy initiatives during the global financial crisis. Journal of International Economics, 87(1), 162-177. http://dx.doi.org/10.1016/j.jinteco.2011.12.001

Allen, F., \& Carletti, E. (2010). An Overview of the Crisis: Causes, Consequences, and Solutions. International Review of Finance, 10(1), 1-26. http://dx.doi.org/10.1111/j.1468-2443.2009.01103.x

Arestis, P., Sobreira, R. R., \& Oreiro, J. L. S. (2011). The financial crisis: origins and implications. Palgrave Macmillan.

Bartram, S. M., \& Bodnar, G. M. (2009). No place to hide: The global crisis in equity markets in 2008/2009.

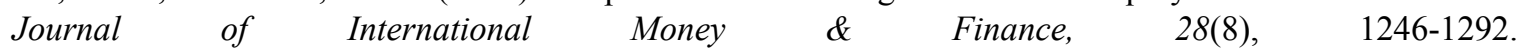


http://dx.doi.org/10.1016/j.jimonfin.2009.08.005

Billio, M., \& Pelizzon, L. (2003). Contagion and interdependence in stock markets: Have they been misdiagnosed? Journal of Economics and Business, 55(5-6), 405-426. http://dx.doi.org/10.1016/S0148-6195(03)00048-1

Bollerslev, T. (1986). Generalized autoregressive conditional heteroskedasticity. Journal of Econometrics, 31(3), 307-327. http://dx.doi.org/10.1016/0304-4076(86)90063-1

Bollerslev, T. (1990). Modelling the coherance in short-run nominal exchange rates: A multivariate generalized arch model. Review of Economics \& Statistics, 72(3), 498. http://dx.doi.org/10.2307/2109358

Caramazza, F., Ricci, L., \& Salgado, R. (2004). International financial contagion in currency crises. Journal of International Money and Finance, 23(1), 51-70. http://dx.doi.org/10.1016/j.jimonfin.2003.10.001

Claessens, S., \& Forbes, K. (Eds.). (2001). International financial contagion. Boston: London Kluwer Academic Publishers. http://dx.doi.org/10.1007/978-1-4757-3314-3

Claessens, S., Dell'Ariccia, G., Igan, D., \& Laeven, L. (2010). Cross-country experiences and policy implications from the global financial crisis. Economic Policy, 25(62), 267-293. http://dx.doi.org/10.1111/j.1468-0327.2010.00244.x

Corsetti, G., Pericoli, M., \& Sbracia, M. (2005). 'Some contagion, some interdependence': More pitfalls in tests of financial contagion. Journal of International Money and Finance, 24(8), 1177-1199. http://dx.doi.org/10.1016/j.jimonfin.2005.08.012

Dooley, M., \& Hutchison, M. (2009). Transmission of the U.S. subprime crisis to emerging markets: Evidence on the decoupling-recoupling hypothesis. Journal of International Money \& Finance, 28(8), 1331-1349. http://dx.doi.org/10.1016/j.jimonfin.2009.08.004

Dornbusch, R., Park, Y. C., \& Claessens, S. (2000). Contagion: Understanding How It Spreads. The World Bank Research Observer, 15(2), 177-197. http://dx.doi.org/10.1093/wbro/15.2.177

Dungey, M., Fry, R., Gonzalez-Hermosillo, B., \& Martin, V. L. (2005). Empirical Modelling of contagion: a review of methodologies. Quantitative Finance, 5(1), 9-24. http://dx.doi.org/10.1080/14697680500142045

Engle, R. (2002). Dynamic Conditional Correlation: A Simple Class of Multivariate Generalized Autoregressive Conditional Heteroskedasticity Models. Journal of Business \& Economic Statistics, 20(3), 339-350. http://dx.doi.org/10.1198/073500102288618487

Forbes, K. J., \& Rigobon, R. (2002). No Contagion, Only Interdependence: Measuring Stock Market Comovements. Journal of Finance, 57(5), 2223-2261. http://dx.doi.org/10.1111/0022-1082.00494

Gklezakou, T., \& Mylonakis, J. (2010). Links and interdependence of developed stock markets under global economic crisis conditions. Journal of Financial Services Marketing, 14(4), 314-327. http://dx.doi.org/10.1057/fsm.2009.24

Guo, F., Chen, C. R., \& Huang, Y. S. (2011). Markets contagion during financial crisis: A regime-switching approach. International Review of Economics \& Finance, 20(1), 95-109. http://dx.doi.org/10.1016/j.iref.2010.07.009

Gupta, R., \& Donleavy, G. D. (2009). Benefits of diversifying investments into emerging markets with time-varying correlations: An Australian perspective. Journal of Multinational Financial Management, 19(2), 160-177. http://dx.doi.org/10.1016/j.mulfin.2008.10.001

Gupta, R., \& Guidi, F. (2012). Cointegration relationship and time varying co-movements among Indian and Asian developed stock markets. International Review of Financial Analysis, 21, 10-22. http://dx.doi.org/10.1016/j.irfa.2011.09.001

Hwang, J. K. (2012). Dynamic Correlation Analysis of Asian Stock Markets. International Advances in Economic Research, 18(2), 227-237. http://dx.doi.org/10.1007/s11294-012-9343-6

Karolyi, G. A. (2003). Does International Financial Contagion Really Exist? International Finance, 6(2), 179. http://dx.doi.org/10.1111/1468-2362.00114

Kearney, C. (2000). The determination and international transmission of stock market volatility. Global Finance Journal, 11(1-2), 31-52. http://dx.doi.org/10.1016/S1044-0283(00)00015-6

Kenourgios, D., Samitas, A., \& Paltalidis, N. (2011). Financial crises and stock market contagion in a multivariate time-varying asymmetric framework. Journal of International Financial Markets, Institutions 
and Money, 21(1), 92-106. http://dx.doi.org/10.1016/j.intfin.2010.08.005

Khalid, A. M., \& Kawai, M. (2003). Was financial market contagion the source of economic crisis in Asia?: Evidence using a multivariate VAR model. Journal of Asian Economics, 14(1), 133. http://dx.doi.org/10.1016/S1049-0078(02)00243-9

Kuper, G. H., \& Lestano. (2007). Dynamic conditional correlation analysis of financial market interdependence: An application to Thailand and Indonesia. Journal of Asian Economics, 18(4), 670-684. http://dx.doi.org/10.1016/j.asieco.2007.03.007

Marcal, E. F., Valls Pereira, P. L., Martin, D. M. L., \& Nakamura, W. T. (2011). Evaluation of contagion or interdependence in the financial crises of Asia and Latin America, considering the macroeconomic fundamentals. Applied Economics, 43(19), 2365-2379. http://dx.doi.org/10.1080/00036840903194204

Markwat, T., Kole, E., \& van Dijk, D. (2009). Contagion as a domino effect in global stock markets. Journal of Banking \& Finance, 33(11), 1996-2012. http://dx.doi.org/10.1016/j.jbankfin.2009.05.008

Mishkin, F. S. (2011). Over the Cliff: From the Subprime to the Global Financial Crisis. The Journal of Economic Perspectives, 25(1), 49-70. http://dx.doi.org/10.1257/jep.25.1.49

MSCI. (2012). MSCI Frontier Markets Indices. Retrieved from $\mathrm{http}: / /$ www.msci.com/products/indices/country_and_regional/fm/

Naoui, K., Liouane, N., \& Brahim, S. (2010). A Dynamic Conditional Correlation Analysis of Financial Contagion: The Case of the Subprime Credit Crisis. International Journal of Economics \& Finance, 2(3), 85-96.

Phylaktis, K., \& Ravazzolo, F. (2002). Measuring financial and economic integration with equity prices in emerging markets. Journal of International Money and Finance, 21(6), 879-903. http://dx.doi.org/10.1016/S0261-5606(02)00027-X

Pretorius, E. (2002). Economic determinants of emerging stock market interdependence. Emerging Markets Review, 3(1), 84-105. http://dx.doi.org/10.1016/S1566-0141(01)00032-2

Syllignakis, M. N., \& Kouretas, G. P. (2011). Dynamic correlation analysis of financial contagion: Evidence from the Central and Eastern European markets. International Review of Economics \& Finance, 20(4), 717-732. http://dx.doi.org/10.1016/j.iref.2011.01.006

Yiu, M. S., Alex-Ho, W. Y., \& Choi, D. F. (2010). Dynamic correlation analysis of financial contagion in Asian markets in global financial turmoil. Applied Financial Economics, 20(4), 345-354. http://dx.doi.org/10.1080/09603100903494946

Yu, I. W., Fung, K. P., \& Tam, C. S. (2010). Assessing financial market integration in Asia - Equity markets. Journal of Banking \& Finance, 34(12), 2874-2885. http://dx.doi.org/10.1016/j.jbankfin.2010.02.010

\section{Notes}

Note 1. The market classification is based on the 2012 MSCI global equity indices.

Note 2. In case that volatilites of markets are simultaneous increase during times of crisis, an interdependent linkage is suggested.

Note 3. Multiple equilibrium relates to changes in expectations of investors that are subject to multiple quilibriums. 